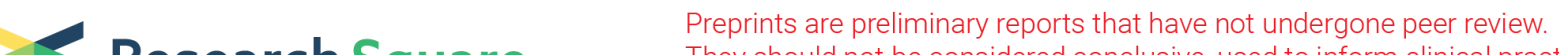 Research Square They should not be considered conclusive, used to inform clinical practice, or referenced by the media as validated information.
}

\section{In Vitro Propagation via Organogenesis and Formation of Globular Bodies of Salvia Plebeia: A Valuable Medicinal Plant}

\section{Qinggui Wu}

Mian Yang Normal University

Honglin Yang

Mian Yang Normal University

\section{Yuxi Sun}

Mian Yang Normal University

Jinyao Hu

Mian Yang Normal University

\section{Lijuan Zou ( $\square$ ljzou66@163.com )}

Mian yang normal university https://orcid.org/0000-0002-9305-6729

\section{Research article}

Keywords: Salvia plebeia R. Brown, Organogenesis, Globular bodies, Propagation, Thidiazuron

Posted Date: July 14th, 2020

DOl: https://doi.org/10.21203/rs.3.rs-39443/v1

License: (9) This work is licensed under a Creative Commons Attribution 4.0 International License.

Read Full License

Version of Record: A version of this preprint was published at In Vitro Cellular \& Developmental Biology Plant on September 13th, 2021. See the published version at https://doi.org/10.1007/s11627-021-10223y. 


\section{Abstract}

Background: As a highly valued medicinal plant, Salvia plebeia R. Brown belongs to the Lamiaceae family that has been subjected to over exploitation in its natural habitat for phytochemical and pharmacological studies. Alternative collection methods need to be developed for the large-scale propagation of Salvia plebeian.

Results: Here, efficient and simple, direct organogenesis (from shoot tips and cotyledonary nodes explants) and Globular bodies (GBs) induction (from hypocotyl explants) systems were developed for the in vitro propagation of Salvia plebeia. The highest and number of regenerated shoots $(7.0 \pm 0.82)$ per shoot tips was obtained on Murashige and Skoog (MS) medium supplemented with a combination of 0.1 $\mathrm{mg} \mathrm{L}^{-1}$ indole-3-acetic acid (IAA) and $1.0 \mathrm{mg} \mathrm{L}^{-1}$ 6-benzyladenine (6-BA), the proliferation of shoots and shoots rooted were carried out on the same medium treatments almost synchronously. Similarly, MS medium supplemented with $0.1 \mathrm{mg} \mathrm{L}^{-1} \mathrm{IAA}$ and $1.0 \mathrm{mg} \mathrm{L}^{-1}$ thidiazuron (TDZ) yielded the maximum number of shoots (37.5 \pm 1.34 ) with $100 \%$ shoot sprouting frequency. Simultaneously, a protocol was developed for GBs induction from hypocotyl explants, and it produced $17.4 \mathrm{GBs}$ per explant with $82.7 \%$ response on MS medium supplemented with TDZ $\left(1.0 \mathrm{mg} \mathrm{L}^{-1}\right)$ and IAA $\left(0.1 \mathrm{mg} \mathrm{L}^{-1}\right)$, and produced GBs that were morphologically similar to globular embryos and successfully germinated on hormone-free MS medium. The acclimatized plantlets with well-developed root systems were successfully shifted to the natural soils with a $100 \%$ survival rate.

Conclusions: Taken together, this protocol can be efficiently used for mass propagation, germplasm preservation and likely also for gene transfer of Salvia plebeia.

\section{Background}

Salvia plebeia R. Brown (S. plebeia) belongs to the family Lamiaceae and genus Salvia. Many Salvia species have been used as herbal medicines all around the world since ancient times (Ulubelen et al. 2002). S. plebeia is an annual or biennial herb famous for its medicinal properties, and it is distributed in China, South Korea, Japan, India, Iran and Australia. This plant is extensively used in traditional systems of medicine in many parts of the world (Bang et al. 2016; Seo et al. 2019). In China, S. plebeia is popularly known as "Ha-Ma-cao/狪" or "Li-Zhi-Cao/怄", and it is distributed mainly in Anhui, Zhejiang and Jiangsu provinces. As a traditional Chinese herb, S. plebeia has a huge potential to be used in traditional prescriptions and home health remedies (Bang et al. 2016). S. plebeia was first recorded 490 years ago in the Compendium of Materia Medica, which was written in the Ming dynasty by Shizhen Li, a famous Chinese medicine master. There are 21 traditional prescriptions that contain $S$. plebeia. In recent years, $S$. plebeia has attracted considerable scientific attention due to its immense medicinal properties. The whole-plant can be used as a medicine and has been extensively explored in traditional as well as modern therapeutic practices for the treatment of numerous inflammatory diseases, such as nephritis, cough, hepatitis, diarrhoea, haemorrhoids, rheumatoid arthritis and even tumours (Liang et al. 2020; Choi et al., 2015; Jin et al. 2008; Jung et al., 2009). Thus far, phytochemical studies have revealed the presence 
of diterpenoids, flavonoids, lignans and sesquiterpenoids in this herb, which exhibits various biological activities, such as antioxidant (Wang et al. 2018), antiproliferative (Ma et al. 2017; Jung et al. 2009), antiviral (Bang et al. 2016), and anti-inflammatory (Zou et al. 2018; Akram et al. 2015; Jung et al. 2009;), and anti-obesity (Choiet al. 2016) properties.

In summary, S. plebeia presents important medicinal values; thus, further studies are required to provide more evidences for its therapeutic uses and to develop new medicines to improve the human health. $S$. plebeia is a highly valued medicinal plant that has been subjected to over exploitation in its natural habitat for phytochemical and pharmacological studies. The conventional propagation of S. plebeia is exclusively through seeds only. The disadvantage of seed germination is that it is easily restricted by temperature conditions, such as proper light and temperature. In addition, the wide-ranging plants are being large-scale collected indiscriminately and unsustainably due to their ethnomedicinal properties, and they are also affected by habitat destruction and deforestation.

Therefore, alternative collection methods need to be developed for the large-scale propagation of $S$. plebeia. The production of medicinal plants through in vitro cultures has been extensively used as a viable and cost-effective tool for plant development, improvement, conservation and scaling up of the plantlet regeneration that involves the production of secondary metabolites (Rai et al. 2011; Cheruvathur et al. 2015).

To the best of our knowledge, micropropagation studies on S. plebeia have not been previously performed. Here, we describe for the first time an efficient system for a rapid clonal propagation via direct organogenesis and GBs formation (not via callus stage) of S. plebeia, using different concentrations and combinations of plant growth regulators (PGRs). In addition, morphologic observations were conducted to confirm the bipolar structure, developmental stages and viability of the GB of S. plebeia.

\section{Methods}

S. plebeia seeds were collected from mature plants, no permission is required to collect these seeds. The seeds were authenticated by Professor Minghua Luo of Mianyang Normal University. The voucher specimen of this material has been deposited in a publicly available herbarium. The seeds were surfacesterilized using $70 \%(\mathrm{v} / \mathrm{v})$ ethanol for $45 \mathrm{~s}$, followed by $0.1 \%(\mathrm{wt} / \mathrm{vol})$ mercuric chloride $\left(\mathrm{HgCl}_{2}\right)$ for $4 \mathrm{~min}$, supplemented by few drops of Tween 20, and then they were washed in sterile distilled water and set to germinate on medium (Murashige and Skoog 1962) fortified with $1.0 \mathrm{mg} \mathrm{L}^{-1}$ gibberellic acid $\left(\mathrm{GA}_{3}\right)$. All PGRs were purchased from Sigma-Aldrich (San Francisco, CA). MS basal medium was gelled with $3 \%$ $(\mathrm{w} / \mathrm{v})$ sucrose, and the $\mathrm{pH}$ was set to 5.8 before adding $0.6 \%(\mathrm{w} / \mathrm{v})$ ager and autoclaving at $121^{\circ} \mathrm{C}$ for $15 \mathrm{~min}$. Dimensions of petri dishes is $9 \mathrm{~cm}$ in diameter. The shape of culture bottle is cylindrical, with a diameter of $7.0 \mathrm{~cm}$ and a height of $8.0 \mathrm{~cm}$. The cultures were maintained at a temperature of $25 \pm 2{ }^{\circ} \mathrm{C}$ and light intensity of $40 \mu \mathrm{mol} \mathrm{m} \mathrm{m}^{-2} \mathrm{~s}^{-1}$, which was provided by cool white fluorescent light (Philips, China) under a 16-h photoperiod in all experiments. Shoot tips, cotyledonary nodes and hypocotyls were excised from 16-day-old in vitro germinated seedlings are used as explants for experimentation. 
In vitro plant regeneration via organogenesis

Shoot tips and cotyledonary nodes (with two cotyledons) were grown on petri dishes with in a vertical orientation, and cultured on MS basal media supplemented with 0.5, 1.0 and $2.0 \mathrm{mg} \mathrm{L}^{-1}$ 6-Benzyladenine (BA) or thidiazuron (TDZ) in combination with a lower concentration $\left(0.1 \mathrm{mg} \mathrm{L}^{-1}\right)$ of indole-3-acetic acid (IAA) or 1-naphthalene acetic acid (NAA). The PGRs were the products of Sigma-Aldrich (St. Louis, MO, USA), and 12-14 explants were cultured per petri dish. The number of explants initiating shoot buds and the average number of shoot buds per explant were recorded after 6 weeks. In each treatment, 50 explants were used, and the experiment was repeated three times.

\section{Globular bodies (GBs) induction from hypocotyl explants}

For GB induction, in vitro hypocotyl explants (1.0-1.5 cm in length, with radicle) used as explants were flatted onto a petri dish, and cultured on MS medium containing $1.0 \mathrm{mg} \mathrm{L}^{-1} \mathrm{TDZ}$ or 6-BA in combination with $0.1 \mathrm{mg} \mathrm{L}^{-1}$ IAA. After a total of 5 weeks of culture, the GB induction process was recorded. After another 2 weeks of culture, plant recovery from GB was investigated. In each treatment, 50 explants were used, and the experiment was repeated three times.

\section{Shoot proliferation, elongation, root formation and transplanting}

Short adventitious buds clusters were cultured on MS medium containing $0.2 \mathrm{mg} \mathrm{L}^{-1} \mathrm{NAA}, 1.0 \mathrm{mg} \mathrm{L}^{-1} \mathrm{BA}$ and along with $0.5 \mathrm{mg} \mathrm{L}^{-1} \mathrm{GA}_{3}$ for proliferation and elongation. The regenerated shoot buds were transferred to the half-strength MS medium containing $0.5,1.0$ and $1.5 \mathrm{mg} \mathrm{L}^{-1}$ IBA or NAA, and were cultured for 15 days to induce the growth of shoots and roots. After 2 weeks of culture, the percentage of rooted shoots was evaluated. The in vitro rooted shoots were harvested and were moved to plastic pots containing a 3:1 ( $/ / \mathrm{v})$ mixture of peat and perlite after acclimatization and irrigated with tapwater every 4-5 days. These plantlets were maintained in the greenhouse under shade $(70 \%)$ at $25 \pm 5^{\circ} \mathrm{C}$ under natural photoperiod conditions.

\section{Statistical analysis}

In each treatment, 50 explants were used, and all experiments were repeated three times. All treatments were prepared in duplicated. The data were separated by a one-way analysis of variance (ANOVA), and the treatment means were considered to be significantly different from the controls by the Least Significant Difference (LSD) test at $P \leq 0.05$ using SPSS v. 18.0" (IBM, USA)

\section{Results}

At the beginning of the experiment, $S$. plebeia seeds were germinated on MS medium fortified with $1.0 \mathrm{mg}$ $\mathrm{L}^{-1} \mathrm{GA}_{3}$ at the rate of $100 \%$ (Fig. 1A). Since no previous information on the regeneration protocols of $S$. plebeia have been reported, the shoot tips, cotyledonary nodes (with two cotyledon) and hypocotyl (with 
radicle) of in vitro-grown seedlings were initially investigated on MS regeneration media after 16 days after inoculated. All three explant types displayed a regeneration response under the conditions (data not shown); therefore, they all would be used for subsequent further studies.

\section{Screening Of Hormones}

When MS medium was fortified with the same concentrations of cytokinins (TDZ and 6-BA), shoot tips explants were produced directly by adventitious shoot buds within 36 days of culture. On the culture media, buds with variable sizes were induced by the shoot-tip explants. The frequency of shoot induction and mean number of shoots varied with the explant cytokinins type (data not shown). TDZ had a significant positive effect on adventitious shoot formation and produced relatively shorter shoots than the 6-BA (Fig. 1B); however, the impact of 6-BA on the elongation and growth of shoot tips was superior to that of the adventitious shoot proliferation and adventitious roots growth of TDZ (Fig. 1C). Therefore, 6BA was used for shoot tips regeneration and TDZ was used for cotyledonary nodes organogenesis in subsequent experiments.

For shoot tips organogenesis, the effect of combination of concentration of 6-BA $\left(0.5,1.0,1.5 \mathrm{mg} \mathrm{L}^{-1}\right)$ alone or with different auxin IAAs or NAAs on shoot regeneration was also tested (data not shown). Shoot tips were inoculated on medium for 36 days, and the inclusion of IAA at $0.1 \mathrm{mg} \mathrm{L}^{-1}$ to the MS medium containing $1.0 \mathrm{mg} \mathrm{L}^{-1} 6-\mathrm{BA}$ significantly increased the mean number of shoots and shoot elongation per explant, and was simultaneously accompanied by the emergence of mass adventitious roots (Fig. 2AB). The mean number of shoots and root significantly reduced when the medium was supplemented with $0.1 \mathrm{mg} \mathrm{L}^{-1}$ IAA and $1.0 \mathrm{mg} \mathrm{L}^{-1} \mathrm{BA}$ (Fig. 2AB). Therefore, IAA was used in subsequent experiments.

Effect of PGRs on adventitious shoot regeneration from shoot tips and cotyledonary node explants of S. plebeia

\section{Adventitious shoot regeneration and morphogenesis from shoot tips}

Adventitious shoot regeneration and morphogenesis in vitro were achieved from shoot tips explants. Initially, the shoot tips grew straight up after 16 days of culture, few pale yellow calli formation was observed at the basal end of the explant (Fig. 3B), a small scale of buds appeared from the base of the shoot tips after 24 days of culture (Fig. $3 \mathrm{C}$ ), and these buds were gradually lengthened into leafy shoots within 36 days. An increased number of buds was produced and accompanied by mass adventitious roots growth (Fig. 3D), and greater shoot numbers and length were observed after 43 days (Fig. 3E).

Data on multiple shoot induction from the shoot tip explants cultured on MS medium with different concentrations of 6-BA alone or combined with $0.1 \mathrm{mg} \mathrm{L}^{-1}$ IAA are presented in Table 1. The inclusion of IAA is essential for shoot tips organogenesis (Fig. 2C). Combinations of IAA and 6-BA were more effective 
for shoot regeneration in this study, and yielded significantly higher shoot numbers and lengths (Table 1; Fig. 3DE). These cultures induced broad leaves (approximately, $0.6 \times 2.0 \mathrm{~cm}$ ). In addition, $1.0 \mathrm{mg} \mathrm{L}^{-1} 6-\mathrm{BA}$ and IAA $0.1 \mathrm{mg} \mathrm{L}^{-1}$ produced the maximum number of shoots per explant, and a higher 6-BA concentration $\left(2.0 \mathrm{mg} \mathrm{L}^{-1}\right)$ decreased both the frequency of shoot induction and mean number of shoots per explant (Table 1). In our study, the growth and proliferation of shoots and rooting of shoots were carried out using the same medium treatments (Fig. 3DE). The rooting of shoots and root length were strongly affected by the medium containing IAA $\left(0.1 \mathrm{mg} \mathrm{L}^{-1}\right)$ (Table 1, Fig. $\left.2 \mathrm{C}\right)$. The rooted shoots were acclimatized ex vitro (100\%), and these roots were thick and white in colour (Fig. 3DE). However, the highest number $(7.0 \pm 0.82)$ of shoots was achieved for direct adventitious shoots from per explants of $S$. plebeia in $0.1 \mathrm{mg} \mathrm{L}^{-1}$ IAA and $1.0 \mathrm{mg} \mathrm{L}^{-1}$ 6-BA with 95.4\% frequency (Table 1). The present investigation showed that the concentration and combination of PGRs played a vital role in enhancing of healthy shoots.

Table 1

Effect of PGRs on adventitious shoot regeneration from shoot tips explants of S. plebeia

\begin{tabular}{|c|c|c|c|c|c|c|}
\hline \multicolumn{2}{|c|}{ PGRs } & \multirow{2}{*}{$\begin{array}{l}\text { Shoot sprouting } \\
\text { frequency (\%) }\end{array}$} & \multirow{2}{*}{$\begin{array}{l}\text { Shoot } \\
\text { (explant } \\
\text { 1) }\end{array}$} & \multirow{2}{*}{$\begin{array}{l}\text { Shoot length } \\
\text { (cm) }\end{array}$} & \multirow{2}{*}{$\begin{array}{l}\text { Roots } \\
\text { (explant }^{-1} \text { ) }\end{array}$} & \multirow{2}{*}{$\begin{array}{l}\text { Root length } \\
\text { (cm) }\end{array}$} \\
\hline IAA & $\begin{array}{l}\text { 6- } \\
\text { BA }\end{array}$ & & & & & \\
\hline & 0.5 & $62.4 \pm 1.36 \mathrm{~d}$ & $\begin{array}{l}2.4 \pm \\
0.17 \mathrm{c}\end{array}$ & $0.6 \pm 0.05 c$ & $1.7 \pm 0.24 d$ & $0.8 \pm 0.07 c$ \\
\hline & 1.0 & $77.5 \pm 2.21 \mathrm{c}$ & $\begin{array}{l}3.2 \pm \\
1.07 \mathrm{bc}\end{array}$ & $1.0 \pm 0.13 b$ & $4.1 \pm 0.21 c$ & $1.3 \pm 0.14 \mathrm{bc}$ \\
\hline & 2.0 & $72.4 \pm 3.51 \mathrm{~cd}$ & $\begin{array}{l}3.5 \pm \\
0.58 \mathrm{~b}\end{array}$ & $1.1 \pm 0.11 \mathrm{ab}$ & $4.4 \pm 0.35 c$ & $1.2 \pm 0.31 \mathrm{bc}$ \\
\hline 0.1 & 0.5 & $87.5 \pm 1.72 b$ & $\begin{array}{l}3.7 \pm \\
0.36 \mathrm{~b}\end{array}$ & $1.2 \pm 0.04 a$ & $8.7 \pm 0.43 b$ & $2.4 \pm 0.58 \mathrm{ab}$ \\
\hline 0.1 & 1.0 & $95.4 \pm 1.21 \mathrm{a}$ & $\begin{array}{l}7.0 \pm \\
0.82 \mathrm{a}\end{array}$ & $1.6 \pm 0.08 a$ & $12.4 \pm 0.59 a$ & $3.5 \pm 0.32 a$ \\
\hline 0.1 & 2.0 & $92.7 \pm 2.42 \mathrm{ab}$ & $\begin{array}{l}5.1 \pm \\
0.32 \mathrm{ab}\end{array}$ & $1.3 \pm 0.07 a$ & $10.0 . \pm 0.31 \mathrm{ab}$ & $3.3 \pm 0.17 a$ \\
\hline
\end{tabular}

Adventitious shoot regeneration and morphogenesis from cotyledonary nodes

In this study, a highly efficient micropropagation system, capable of sustainable multiplications of shoots, has been developed for S. plebeia using cotyledonary nodes (with two cotyledons) explants obtained from in vitro seedlings (Fig. 3F). Two axillary shoots were developed from cotyledonary nodes (Fig. 3G). Auxins were found to be essential for the development of multiple shoots. After 24 days of 
culture on MS medium supplemented with $0.1 \mathrm{mg} \mathrm{L}^{-1}$ IAA and $\operatorname{TDZ}\left(0.5,1.0,1.5 \mathrm{mg} \mathrm{L}^{-1}\right)$ or alone, all the shoot tips and $77.4-100 \%$ of the internode developed axillary shoots did not present callus formation (Table 2, Fig. 3H). After 36 days of culture, a great number of adventitious buds emerged from the basal of axillary bud of cotyledonary nodes (Fig. 3I) under 10 days of extended culture and clusters of adventitious buds formed and the average length of the shoots was shortened (Fig. 3J). Based on the results presented in Table 2, the best multiplication results were recorded when the cotyledonary nodes explants were cultured on medium containing $0.1 \mathrm{mg} \mathrm{L}^{-1} \mathrm{IAA}$ and $1.0 \mathrm{mg} \mathrm{L}^{-1} \mathrm{TDZ}$, and the mean shoot number was approximately $37.5 \pm 1.34$ per explant with $100 \%$ shoot sprouting frequency (Table 2 ).

Table 2

Effect of PGRs on in vitro regeneration from internode explants of S. plebeia

\begin{tabular}{|c|c|c|c|}
\hline \multicolumn{2}{|c|}{ PGRs } & \multirow[t]{2}{*}{ Shoot sprouting frequency (\%) } & \multirow{2}{*}{ Shoot (explant $\left.{ }^{-1}\right)$} \\
\hline IAA & TDZ & & \\
\hline & 0.5 & $77.4 \pm 2.77 c$ & $14.3 \pm 2.1 \mathrm{c}$ \\
\hline & 1.0 & $87.5 \pm 2.45 b$ & $17.7 \pm 0.58 c$ \\
\hline & 2.0 & $86.7 \pm 3.12 b$ & $16.8 \pm 1.19 c$ \\
\hline 0.1 & 0.5 & $94.0 \pm 2.13 a$ & $28.4 \pm 2.27 b$ \\
\hline 0.1 & 1.0 & $100.0 \pm 0.00 \mathrm{a}$ & $37.5 \pm 1.34 a$ \\
\hline 0.1 & 2.0 & $100.0 \pm 0.00 a$ & $30.3 \pm 3.31 b$ \\
\hline
\end{tabular}

\section{Effect Of Pgrs On Gbs From Hypocotyl Explants}

We tested the influence of PGRs on GB induction. With the exception of $1.0 \mathrm{mg} \mathrm{L}^{-1}$ 6-BA, all tested treatments had GB formation from the upper cut surface of the hypocotyl after 24 days of culture. MS media fortified with $0.1 \mathrm{mg} \mathrm{L}^{-1}$ IAA and $1.0 \mathrm{mg} \mathrm{L}^{-1} \mathrm{TDZ}$ induced 17.4 light greenish yellow GBs /explant with a $92.7 \%$ induction rate after 24 days of culture (Table 3; Fig. 4C). The treatment with $1.0 \mathrm{mg} \mathrm{L}^{-1} \mathrm{TDZ}$ produced $10.5 \mathrm{GBs} /$ explant with a $74.5 \%$ induction rate, whereas $0.1 \mathrm{mg} \mathrm{L}^{-1}$ IAA and $1.0 \mathrm{mg} \mathrm{L}^{-1} 6$-BA (3.2 GBs with 11.4\%) yielded a lower number of GBs with a low frequency of induction (Table 3). To obtain plantlets, GBs were transferred to PGR-free medium. Plantlet formation was observed from the second week of culture in most of treatments (Fig. 4DE). After 7 weeks of culture, the rate of GB development into plantlets was above $70 \%$ for the all treatments (Table 3 ). 
Table 3

Effect of PGRs on the formation of GB from hypocotyl explants of S.plebeian

\begin{tabular}{|llll|}
\hline PGRs(mg/L) & $\begin{array}{l}\text { Callus } \\
\text { formation (\%) }\end{array}$ & $\begin{array}{l}\text { Number of nodual embryogenic } \\
\left(\text { explant }^{-1}\right)\end{array}$ & $\begin{array}{l}\text { Average plants recovered from } \\
\text { embryos }\end{array}$ \\
\hline $6-B A 1.0$ & $0 \mathrm{c}$ & $0 \mathrm{c} \pm$ & $0 \mathrm{~d}$ \\
\hline TDZ1.0 & $64.5 \pm 1.9 \mathrm{~b}$ & $10.5 \pm 1.32 \mathrm{~b}$ & $7.0 \pm 0.30 \mathrm{~b}$ \\
\hline $\begin{array}{l}\text { IAA0.1 +6- } \\
\text { BA1.0 }\end{array}$ & $11.4 \pm 0.7 \mathrm{c}$ & $3.2 \pm 0.72 \mathrm{c}$ & $2.0 \pm 0.14 \mathrm{c}$ \\
\hline $\begin{array}{l}\text { IAA0.1+ } \\
\text { TDZ1.0 }\end{array}$ & $82.7 \pm 2.8 \mathrm{a}$ & $17.4 \pm 2.16 \mathrm{a}$ & $12.0 \pm 0.58 \mathrm{a}$ \\
\hline $\begin{array}{l}\text { Values within a column followed by different letters indicate significant differences according to the } \\
\text { LSD test at } P<0.05 \text {. All treatments consisted of } 50 \text { explants and the experiments were repeated three } \\
\text { times }\end{array}$ \\
\hline
\end{tabular}

The morphogenesis analysis revealed various developmental stages of the GBs from the hypocotyl. Initially, the transverse surface of the hypocotyl (not near the radicle) swelled and turned green (Fig. 4B). Green protuberances originated from the epidermis of at the upper end of the hypocotyl and then extended to the GB structure after 24 days of culture (Fig. 4C). Stereomicroscope observations showed an enhanced number of GBs (Fig. 4G and H); in addition, the GBs with bipolar structure developed without any intermediate callus development. During bipolar development, the shoot pole (Fig. $4 \mathrm{l}$ black arrow) produced the shoot tip, heart-shaped embryos (Fig. $4 \mathrm{~J}$ ) and cotyledon-shaped were also observed (Fig. 4K). However, the root pole remained embedded without any root formation on protuberances (Fig. 4I black arrow). GBs successfully germinated and converted into plantlets on hormone-free MS medium (Fig. 4E).

Seedling hypocotyls are preferred for organogenesis and embryogenesis for kinds of species (Karakas et al. 2020; García-Fortea et al. 2020; Banjac et al. 2019; Gerszberg et al. 2015). The present study describes an efficient protocol for S. plebeia GBs (similar to somatic embryogenesis) formation, derived from the hypocotyl.

\section{Shoot Proliferation And Elongation And Root Formation And Transplanting}

For further development of adventitious shoots, the explants were cultivated for 6 weeks on different media (Table 2, 3; Fig. 5A) and then transferred to MS medium containing $0.5 \mathrm{mg} \mathrm{L}^{-1} \mathrm{GA}_{3}$ in combination with $0.2 \mathrm{mg} \mathrm{L}^{-1} \mathrm{NAA}$ and $1.0 \mathrm{mg} \mathrm{L}^{-1}$ 6-BA to elongate growth. Moreover, as the subculture was extended to 2 weeks, the number of well-developed shoots increased significantly (data not shown, Fig. 5BCDE). The well-developed shoots ( $3-5 \mathrm{~cm}$ in length) were excised and transferred to half-MS medium supplemented with NAA $\left(0.1,0.5,1.0 \mathrm{mg} \mathrm{L}^{-1}\right)$ or IBA $\left(0.5,1.0,1.5 \mathrm{mg} \mathrm{L}^{-1}\right)$, and they continued to growth 
and rooted spontaneously (Fig. 5F). Root length and morphogenesis in vitro were observed after 2 weeks of culture according to the media used. The maximum root number $(22.4 \pm 0.42)$ and length $(4.6 \pm$ $0.32 \mathrm{~cm}$ ) per shoot was obtained with half-strength MS medium containing $0.5 \mathrm{mg} \mathrm{L}^{-1}$ NAA (Table 4; Fig. FG). Rooted plantlets were transferred into soil and successfully acclimatized under the greenhouse conditions with $100 \%$ survival rate (Fig. $5 \mathrm{H}$ ).

Table 4

Effects of different culture media on rooting of S. plebeian

\begin{tabular}{|c|c|c|c|c|}
\hline \multicolumn{2}{|l|}{ PGRs } & \multirow[t]{2}{*}{ Rooting (\%) } & \multirow[t]{2}{*}{ Mean no. roots } & \multirow[t]{2}{*}{ Root length (cm) } \\
\hline NAA & IBA & & & \\
\hline & 0.5 & $72.4 \pm 1.37 c$ & $6.3 \pm 2.11 c$ & $1.4 \pm 0.25 b c$ \\
\hline & 1.0 & $87.5 \pm 1.25 b$ & $8.7 \pm 0.32 c$ & $2.3 \pm 0.43 b$ \\
\hline & 1.5 & $80.7 \pm 2.15 b$ & $6.8 \pm 1.19 c$ & $2.1 \pm 0.38 b$ \\
\hline 0.1 & & $91.0 \pm 2.34 a$ & $11.4 \pm 1.62 b$ & $2.4 \pm 0.15 b$ \\
\hline 0.5 & & $100.0 \pm 0.00 a$ & $17.5 \pm 0.43 a$ & $4.6 \pm 0.32 a$ \\
\hline 1.0 & & $100.0 \pm 0.00 a$ & $14.3 \pm 2.31 b$ & $2.7 \pm 0.38 b$ \\
\hline
\end{tabular}

\section{Discussion}

Roots have been was used as explants in many species, and they exhibited low regeneration compared with other explants (Zeng et al., 2019; Banjac et al., 2019; Zou et al., 2017). This experiment indicated that adventitious roots (Fig. 6a) from regenerated plants (Fig. 6A) were placed parallel to the surface of MS medium containing $0.2 \mathrm{mg} \mathrm{L}^{-1} \mathrm{IAA}$ and $2.0 \mathrm{mg} \mathrm{L}^{-1} \mathrm{TDZ}$ (data not shown) led to large-scale of shoot induction. No morphogenesis was observed under PGR free medium. The shoots were developed from the adventitious root explants in an interesting way: firstly, the roots (in some parts) started to swell and then produced compact green callus that formed small balls arranged regularly on the root (Fig. 6B); subsequently, a strange phenomenon occurred in which some root apices formed light green callus, or maintained the absorptive capacity. After 24 days, the proliferation of prolific shoots arose from the green nodal callus (Fig. $6 \mathrm{CD}$ ), and the compact green callus is continuously proliferated and differentiated (Fig. 6C black arrow). As the culture time was extended, prolific shoots covered the root explants (Fig. 6F), and some apices still possessed a distinct root hair zone with absorptive capacity (Fig. 6f). Previous researches has shown that the variety of regeneration abilities among different explants is attributed to variations in the physiological conditions, such as different levels of proteins (Tian et al. 2003) and endogenous hormones (Zeng et al., 2019; Wang et al., 2015). In this study, we found that root explants exhibited regeneration capacity (Fig. 6); however, when we induced GB from hypocotyls (with radicles) as 
explants, we found that the radicles did not respond (Fig. $4 A B C$ ), which may be related to endogenous hormones. Further experiments will be carried out.

Generally, cytokinin was found to be essential for shoot induction and proliferation; however, its type and suitable concentration varies with the species (Tubic et al. 2016; Kumari et al. 2018). TDZ produced superior responses for cotyledonary nodes regeneration than the other cytokinins (6-BA, KT; data not shown) in our study, which might be related to its concentration being appropriate for stimulating endogenous hormones metabolism and inducing the production of endogenous hormones for the induction of multiple shoots. TDZ is one of the most effective plant growth regulators and a derivative of phenyl urea (Kumari et al., 2018), and it is believed to be the best synthetic cytokinin present for the regeneration of numerous plant systems, including Salvia (Sivanesan et al. 2011). TDZ promotes axillary bud proliferation via reducing the dominance of the apical meristem (Silué, et al., 2016; Thomas and Katterman 1986). The high cytokinin activity of TDZ inhibits shoot elongation, while shoot fasciation may be related to the presence of a phenyl group in TDZ (Huetteman and Preece 1993; Kumari et al. 2018). As mentioned in the literature review, the bud breaking started after 16 days and $0.1 \mathrm{mg} \mathrm{L}^{-1} \mathrm{IAA}$ and $1.0 \mathrm{mg} \mathrm{L}^{-1}$ TDZ were found to be optimum for adventitious bud proliferation. The mean shoot number was approximately $37.5 \pm 1.34$ per explant with $100 \%$ induction; thus, we speculate that the presence of auxin facilitates the elongation of buds to balance the reduced dominance of the apical meristem under TDZ. Both the concentration and the exposure duration of TDZ for the explants influenced the frequency of shoot proliferation and elongation (Khanam et al., 2018; Kumar et al. 2018), and this result has been reported in numerous plants species, such as Rauwolfa tetraphylla (Faisal et al. 2005) and Withania somnifera (Fatima and Anis 2011). When cultured on MS basal media with TDZ, the differentiated adventitious bud failed to elongate, even after 2 weeks of incubation (Fig. 3J). This finding could be due to the lack of degradation of TDZ by cytokinin oxidase enzymes present in plant tissues (Zatloukal et al. 2008; Podwyszynska et al. 2014). For shoot elongation, an efficient culture process was followed by their transfer to media without TDZ. Exposure of the adventitious shoots to medium with NAA at $0.2 \mathrm{mg} \mathrm{L}^{-1}, 6-\mathrm{BA}$ at $1.0 \mathrm{mg} \mathrm{L}^{-1}$ and $\mathrm{GA}_{3}$ at $0.5 \mathrm{mg} \mathrm{L}^{-1}$ was effective for shoot elongation (Fig. 5BCDE).

The synergistic effects of PGRs in adventitious shoot proliferation is dependent on cytokinin-cytokinin or cytokinin-auxin in S. plebeia in vitro. Similar effects were also observed in several other species of Salvia (Sivanesan et al. 2015; Sivanesan et al. 2016; Kaul et al. 2013). Sivanesan et al. (2016) reported that the highest number of shoots (17.1) induced per shoot tip explant of $A$. multiflora was observed for MS medium fortified with $8.0 \mathrm{mg} \mathrm{L}^{-1} \mathrm{BA}$ and $2.7 \mathrm{mg} \mathrm{L}^{-1} \mathrm{NAA}$. Consistent with the previous studies, our results indicate that the combination of BA and IAA was important for inducing significantly more shoot production and formation of broad leaf and root formation in S. plebeia (Table 1; Fig. 2C). In addition, our study showed that the combination of 6-BA and IAA induced adventitious buds and roots to a greater degree than the combination of BA and NAA (Fig. 2 AB). In this study, the shoots were rooted in the same treatments. Similar findings have been reported for other plant species (Kumari et al. 2016; Kitamura et al. 2002; Kordi et al. 2013). 


\section{Conclusions}

In the present investigation, a highly efficient system was developed for the micropropagation of $S$. plebeia via direct organogenesis and GB formation through different explants types and using different concentrations and combinations of plant growth regulators (PGRs). Some factors affecting the adventitious shoot and GBs induction and proliferation in S. plebeia have been studied. This method can be useful for germplasm conservation, mass propagation, and genetic engineering processes in $S$. plebeia.

\section{Abbreviations}

IAA indole-3-acetic acid

NAA 1-Naphthalene acetic acid

6-BA 6-benzyladenine

$\mathrm{GA}_{3}$ Gibberellic acid

TDZ Thidiazuron

GBs Globular bodies

\section{Declarations}

Ethics approval and consent to participate: Not applicable.

Consent for publication:Not applicable.

Availability of data and material:Not applicable.

Competing interests:The authors declare that they have no competing interests.

Funding:The work was supported by Applied Basic Project of Sichuan Science and Technology Department (2018JY0192, 2018JY0244), Scientific research initiation project of Mianyang normal university (QD2019A12), the National Natural Science Foundation of China (31972258) and the Open Project from the Ecological Security and Protection Key Laboratory of Sichuan Province (ESP1602), the Open Program of Beijing Key Laoratory of Flavor Chemistry (SPFW2019YB05)

Authors' contributions: LJZ designed and guided the experiments. Qinggui Wu performed the experiments, analyzed the data and wrote the article. HLY, YXS and JYH made substantial contributions to the data analysis and the manuscript revision. All authors read and approved the final manuscript. 
Acknowledgements: We thank professor Minghua Luo Zhang for identifying the authenticity of the seeds of Salvia plebeian.

\section{References}

Akram M, Syed Ahmed S, Kim KA, Lee Jong S, Chang SY, Chul Y, Bae, ON (2015) Heme oxygenase 1mediated novel anti-inflammatory activities of Salvia plebeia and its active components. J. Ethnopharmacol 174: 322-330

Bang S, Quy TK C Ha, Lee et al. (2016) Antiviral activities of compounds from aerial parts of Salvia plebeia R. Br. Journal of ethnopharmacology 192: 398-405

Banjac N, Vinterhalter B, KrstićðMilošević D, Milojević J, Tubić L, Ghalawenji N, ZdravkovićđKorać S (2019) Somatic embryogenesis and shoot organogenesis from the hypocotyl slices and free radical scavenging activity of regenerants of collard greens (Brassica oleracea L. var. acephala). Plant Cell, Tissue and Organ Culture 137:613-626

Cheruvathur MK, Abraham J, Thomas TD (2015) In vitro micropropagation and flowering in Ipomoea sepiaria Roxb. An important ethanomedicinal plant. Asian Pac J Reprod 4(1):49-53

Choi JK, Oh HM, Park JH et al. (2015) Salvia plebeia extract inhibits the inflammatory response in human rheumatoid synovial fibroblasts and a murine model of arthritis. Phytomedicine 22 (3): 415-422

Choi SI, Cho IH, Han SH, Jeon YJ, Choi JG, Kim JS, Lee JH (2016) Antiobesity effects of Salvia plebeia R. Br. extract in high-fat diet-induced obese mice. J. Med. Food 19: 1048-1056

Faisal M, Ahmad N, Anis M (2005) Shoot multiplication in Rauvolfia tetraphylla L. using thidiazuron. Plant Cell Tiss Org Cult 80:187-190

Fatima N, Anis M (2011) Thidiazuron induced high frequency axillary shoot multiplication in Withania somnifera L. (Dunal.). J Medicinal Plants Res 5:6681-6687

García-Fortea E, Lluch-Ruiz A, Pineda-Chaza BJ, García-Pérez A, Bracho-Gil JP, Plazas M, Gramazio P, Vilanova S, Moreno V, Prohens J (2020) A highly efficient organogenesis protocol based on zeatin riboside for in vitro regeneration of eggplant. BMC Plant Biol. 20(1):6

Gerszberg A, Hnatuszko-Konka K, Kowalczyk T (2015) In vitro regeneration of eight cultivars of Brassica oleracea. var. capitata. In Vitro Cell Dev Biol Plant 51:80-87

Huetteman A, Preece EJ (1993) Thidiazuron: a potent cytokinin for woody plant tissue culture. Plant Cell Tiss Org Cult 33:105-119

Jin XF, Lu YH, Wei DZ, Wang ZT (2008) Chemical fingerprint and quantitative analysis of Salvia plebeia R. $\mathrm{Br}$. by high-performance liquid chromatography. J Pharm Biomed 48, 100-104 
Jung HJ, Song YS, Lim CJ, Park EH, (2009) Anti-inflammatory, anti-angiogenic and anti-nociceptive activities of an ethanol extract of Salvia plebeia R. Brown. J Ethnopharmacol 126, 355-360

Karakas FP(2020) Efficient Plant Regeneration and Callus Induction from Nodal and Hypocotyl Explants of Goji Berry (Lycium barbarum L.) and Comparison of Phenolic Profiles in Calli Formed under Different Combinations of Plant Growth Regulators. Plant Physiology and

Biochemistry 10.1016/j.plaphy.2019.11.009

Kaul S, Das S, Srivastava SV (2013) Micropropagation of Ajuga bracteosa, a medicinal herb. Physiol Mol Biol Plants 19:289-296

Khanam MN, Anis M. (2018)Organogenesis and efficient in vitro plantlet regeneration from nodal segments of Allamanda cathartica L. using TDZ and ultrasound assisted extraction of quercetin.Plant Cell Tiss Organ Culture:https://doi.org/10.1007/s11240-018-1416-7

Kordi M, Kaviani B, Hashemabadi D (2013) In vitro propagation of Kalanchoe blossfeldiana using BA and NAA. Eur J Exp Biol 3:285-288

Kitamura Y, Kubo K, Rahman LU, Ikenaga T (2002) Reproduction of Sedum drymarioides, an endangered rare species, by micropropagation. Plant Biotechnol 19:303-309

Kumari A, Baskaran P, Van Staden JV (2016) In vitro propagation and antibacterial activity in Cotyledon orbiculata: a valuable medicinal plant. Plant Cell Tiss Organ Cult 124:97-104

Kumari P, Singh S, Yadav S, Tran LSP (2018) Pretreatment of seeds with thidiazuron delimits its negative effects on explants and promotes regeneration in chickpea (Cicer arietinum L.). Plant Cell Tiss Org Cult 133(1):103-114

Liang YY, Wan XH, Niu FJ, Xie SM, Guo H, Yang HY, Guo LY, Zhou CZ. (2020) Salvia plebeia R. Br.: an overview about its traditional uses, chemical constituents, Pharmacology and Modern Applications 121:109589

Ma LF, Wang PF, Wang JD, Tong XM, Shan WG, Zhang H, Zhan ZJ (2017) New Eudesmane Sesquiterpenoids from Salvia plebeia R. Br. Chem Biodivers 14(8)

Murashige T, Skoog F (1962) A revised medium for rapid growth and bioassay with tobacco tissue culture. Physiol Plant 15: 473-497

Podwyszynska M, Novák O, Doležal K, Strnad M (2014) Endogenous cytokinin dynamics in micropropagated tulips during bulb formation process influenced by TDZ and 2iP pre-treatment. Plant Cell Tiss Org Cult 119: 331-346

Rai MK, Kalia RK, Singh R, Gangola MP, Dhawan AK (2011) Developing stress tolerant plants through in vitro selection-an overview of the recent progress. Environ Exp Bot 71:89-98 
Seo HW, Suh JH, Kyung JS, et al. (2019) Subacute oral toxicity and bacterial mutagenicity study of a mixture of korean red ginseng (CA Meyer) and Salvia plebeia R. Br. extracts, Toxicological research 35(3):215-224

Sivanesan I, Ko CH, Lee JP, Jeong BR (2011) Influence of cytokinins on adventitious shoot regeneration from leaf and petiole explants of Ajuga multiflora Bunge. Propag Ornam Plants 11:156-158

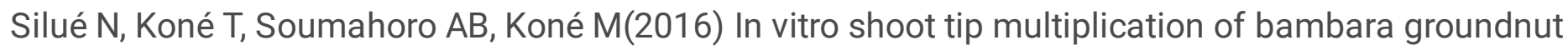
[Vigna subterranea (L.) Verdc.]Plant Cell Tiss Organ Cult 127:603-611

Sivanesan I, Park SW (2015) Effect of plant growth regulators on axillary shoot multiplication from nodal explants of Ajuga multiflora Bunge. Propag Ornam Plants 15:42-44

Sivanesan I, Saini RK, Noorzai R, Zamany AJ, Kim DH (2016) In vitro propagation, carotenoid, fatty acid and tocopherol content of Ajuga multiflora Bunge. 3 Biotech 6(1):91

Thomas JC, Katterman FR (1986) Cytokinin activity induced by thidiazuron. Plant Physiol 81:681-683

Tian M, Gu Q, Zhu MY (2003) The involvement of hydrogen peroxide and antioxidant enzymes in the process of shoot organogenesis of strawberry callus. Plant science 165(4):701-707

Tubic L., SavicJ., Mitic N., Milojevic J., Janosevic D., Budimir S., Snez`ana Zdravkovic'-Korac'S. (2016) Cytokinins differentially affect regeneration, plant growth and antioxidative enzymes activity in chive (Allium schoenoprasum L.)Plant Cell Tiss Organ Cult 124:1-14

Ulubelen A, Birman H, Oksuz S, Topcu G, Kolak U, Barla A, Voelter W (2002) Cardio active Diterpenes from the Roots of Salvia eriophora. Planta Med 68: 818-821

Wang H, Li MF, Yang Y, Dong J, Jin WM (2015) Histological and endogenous plant growth regulators changes associated with adventitious shoot regeneration from in vitro leaf explants of strawberry (Fragaria $\times$ ananassa cv. 'Honeoye'). Plant Cell Tiss Organ Cult 123:479-488

Wang JF, Yan WW, Xu JX, et al. (2018) Research progress in chemical constituents and pharmacological effects of Salvia plebeia R. Br, Journal of hunan university of Chinese medicine 38(04): 482-485

Zatloukal M, Gemrotov M, Dolezal K, Havlıcek L, Spıchal L, Strnad M (2008) Novel potent inhibitors of $A$. thaliana cytokinin oxidase/ dehydrogenase. Bioorg Med Chem 16:9268-9275

Zou YH, Zhao L, Xu YK, Bao JM, Liu X, Zhang JS, Li W, Ahmed A, Yin S, Tang GH (2018) Antiinflammatory sesquiterpenoids from the Traditional Chinese Medicine Salvia plebeia: Regulates proinflammatory mediators through inhibition of NF-KB and Erk1/2 signaling pathways in LPS-induced Raw264.7 cells. Journal of Ethnopharmacology 210:95-106 
Zeng QZ, Han ZQ, Kang XY. (2019)Adventitious shoot regeneration from leaf, petiole and root explants in triploid (Populus alba $\times$ P. glandulosa) $\times$ P. tomentosa. Plant Cell Tiss Org Cul 138:121-130

Zou LJ, Yang JT, Wu QG. (2017) A protocol for rapid and high-frequency in vitro propagation of Solanum nigrum L.Sains Malaysiana 46(8):1183-1189

\section{Figures}

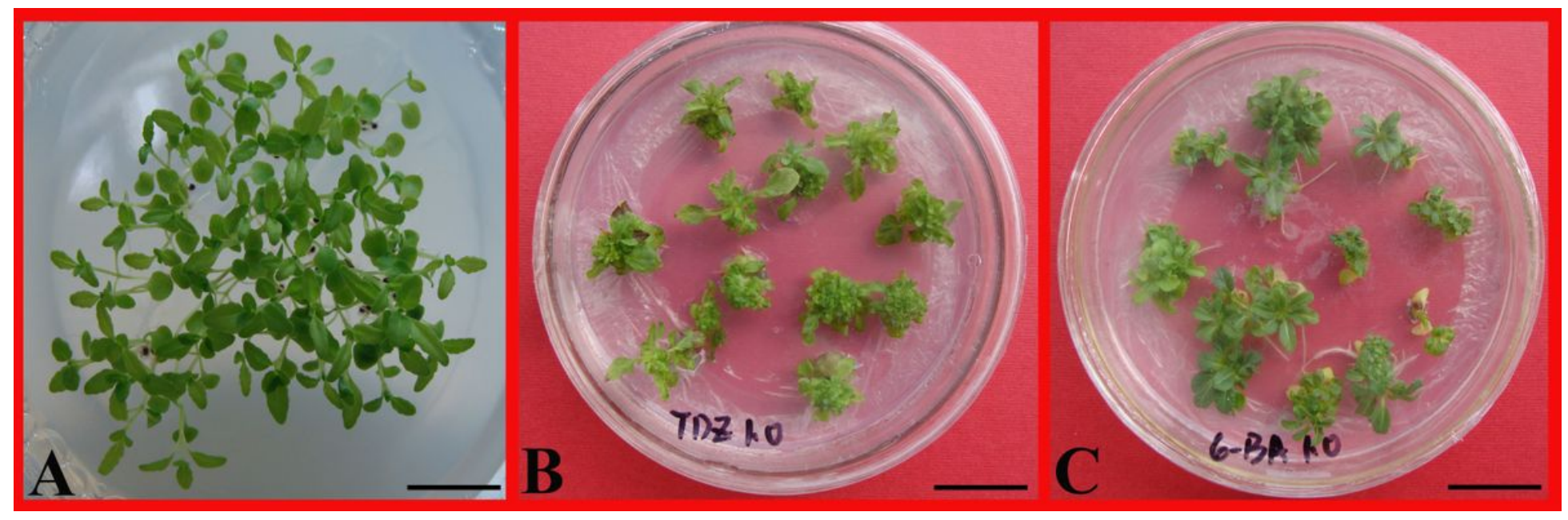

\section{Figure 1}

A Seedlings germinated after 16 days of culture. B and C Development of direct adventitious shoot regeneration on MS medium containing $1.0 \mathrm{mg} / \mathrm{L}$ TDZ (or 6-BA) from the shoot tips after 36 days of culture. Bar=2 cm 


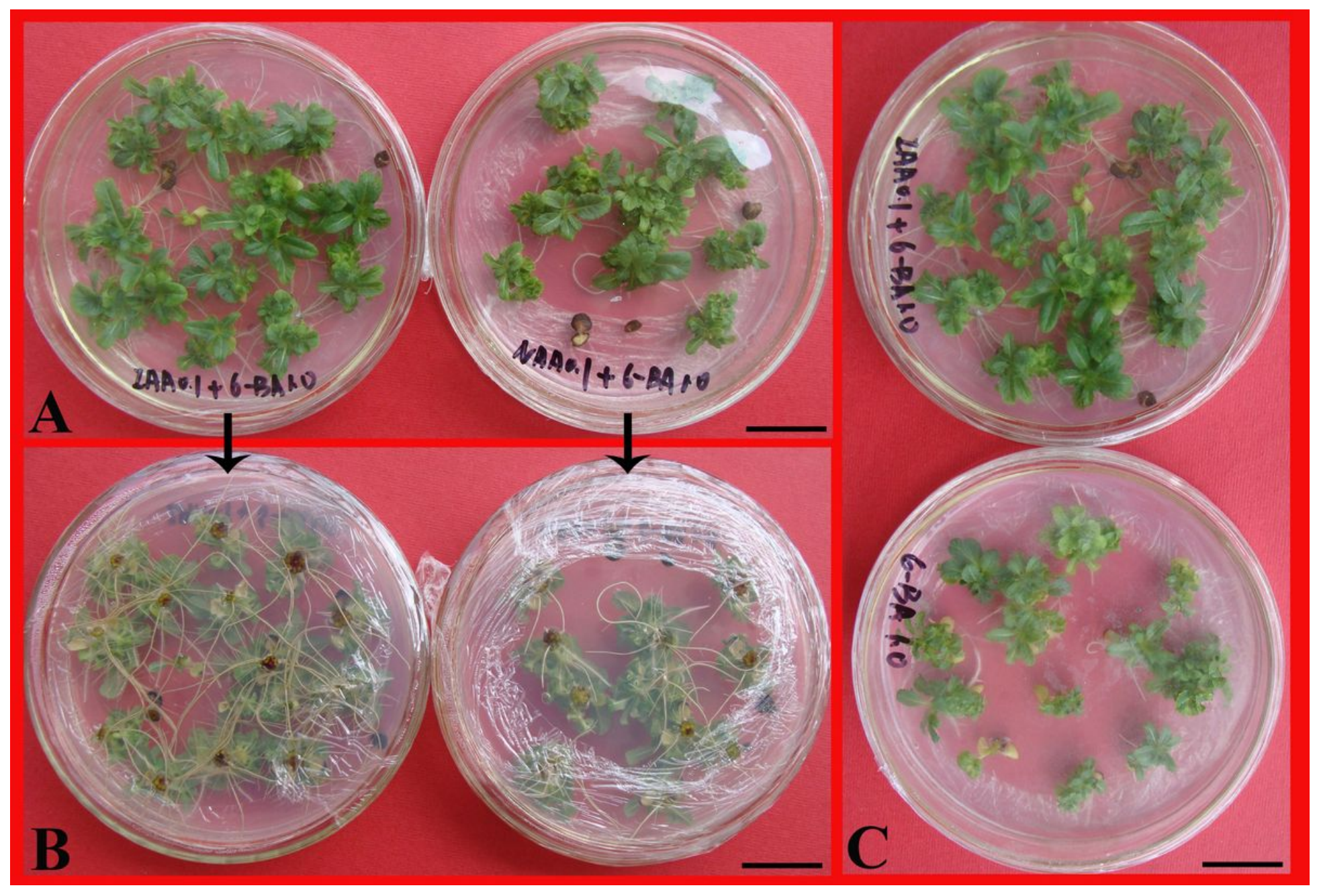

\section{Figure 2}

A Direct adventitious bud induction from shoot tips on MS medium containing $0.1 \mathrm{mg} / \mathrm{L}$ NAA (or IAA) and $1.0 \mathrm{mg} / \mathrm{L} 6-B A$ and roots generated from the bottom of the shoot tips after 36 days. B Reverse side of $A$. C Shoot regeneration in MS medium with $1.0 \mathrm{mg} / \mathrm{L} 6-\mathrm{BA}$ alone or with $0.1 \mathrm{mg} / \mathrm{L}$ IAA after 36 days. Bar=2 $\mathrm{cm}$

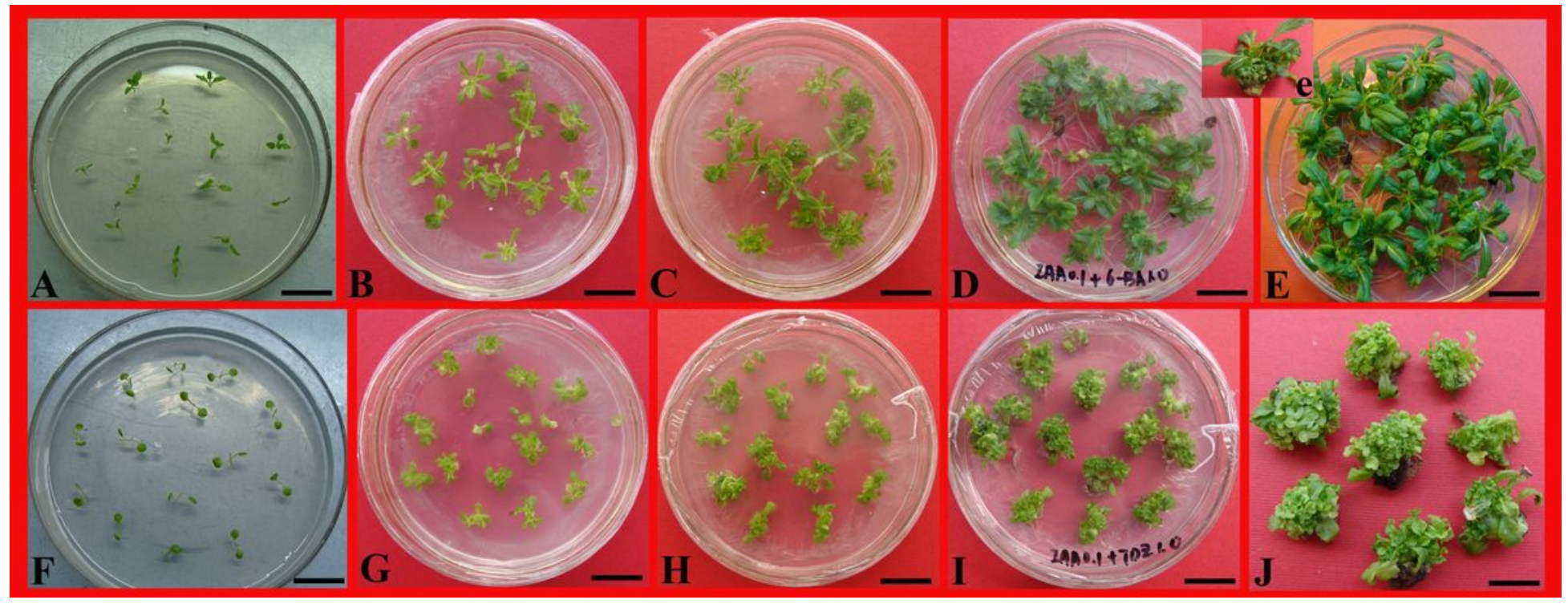




\section{Figure 3}

Direct adventitious shoot regeneration and plant formation from shoot tips (A-E) and cotyledonary node (F-J) explants of Salvia plebeian. A Shoot tip explants. B Shoot tips after 16 days of culture. C Proliferation of shoot tips for 24 days. D and E Development of adventitious shoots on MS medium with $0.1 \mathrm{mg} / \mathrm{L}$ IAA and $1.0 \mathrm{mg} / \mathrm{L}$ 6-BA accompanied by abundant adventitious roots generation from the bottom of the shoot tips after 36 days and 43 days, respectively. F Cotyledonary node explants. $\mathrm{G}$ Cotyledonary nodes after 16 days. H Proliferation of cotyledonary nodes for 24 days. I and $\mathrm{J}$ Development of adventitious shoots on MS medium with $0.1 \mathrm{mg} / \mathrm{L}$ IAA and $1.0 \mathrm{mg} / \mathrm{L} \mathrm{TDZ}$ after 36 days and 43 days of culture, respectively. Bar $=2 \mathrm{~cm}$

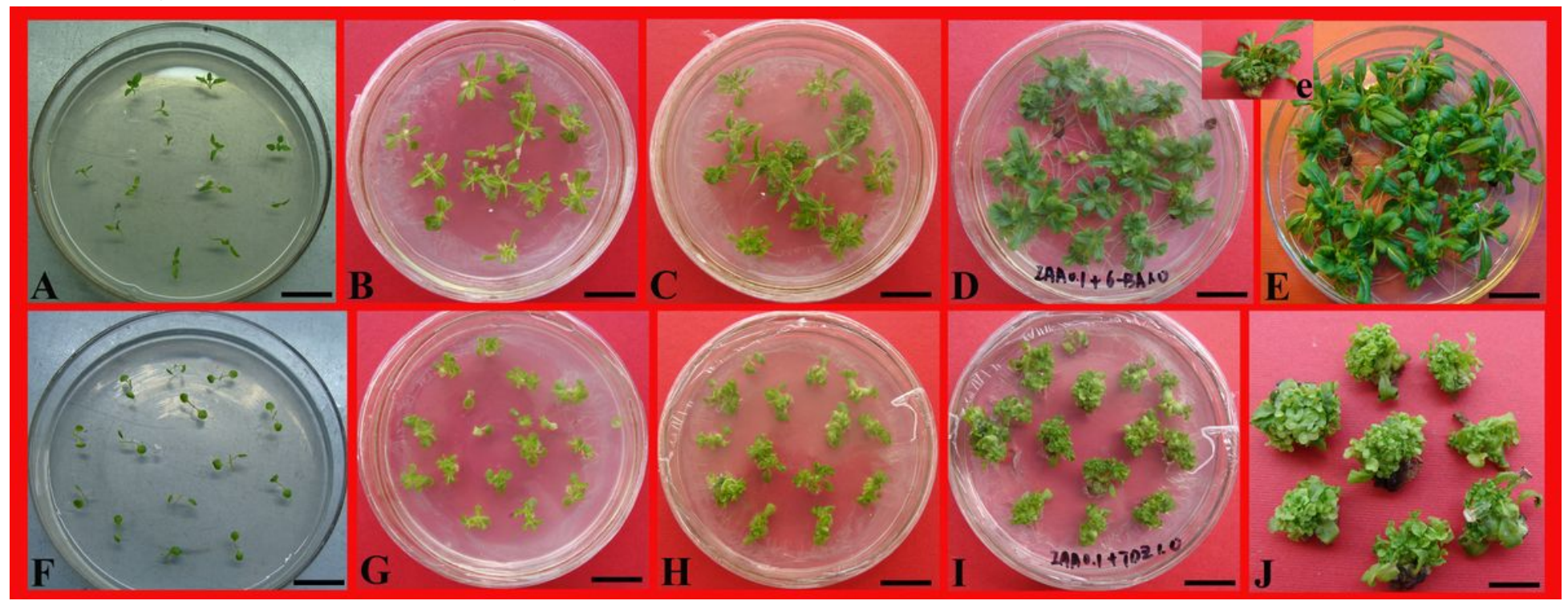

\section{Figure 4}

In vitro propagation through the formation of GBs and morphological observations pf GBs in the multiplication and differentiation stage of Salvia plebeian. A-E In vitro propagation through the formation of GBs. A Hypocotyl explant (with radicle). B Hypocotyl that swelled and became green. C Light greenish yellow GB formation from the hypocotyl after 24 days of culture. D GB development into a cluster of plantlets after 36 days of culture. E Germination of a cluster of GBs after 49 days of culture. Bar $=10 \mathrm{~cm}$. G-H Morphological observation of Salvia plebeian GBs in the multiplication differentiation stage. $\mathrm{G}$ and $\mathrm{H}$ Magnification of $F$ from different angles. GH Multiplication of GBs. The red arrow indicates the globular stage of GBs, and the black arrow indicates the cotyledonary stage of GBs. (I) Globular stage (I, red arrow indicates shoot pole, black arrow indicate root pole) and heart stage $(\mathrm{J})$ of GBs. K GB development into a cluster of plantlets. Bar=2cm (AB), $1 \mathrm{~cm}(C D), 1 \mathrm{~cm}(E), 1.5 \mathrm{~cm}(\mathrm{~F}), 5 \mathrm{~mm}(\mathrm{GHK})$ 


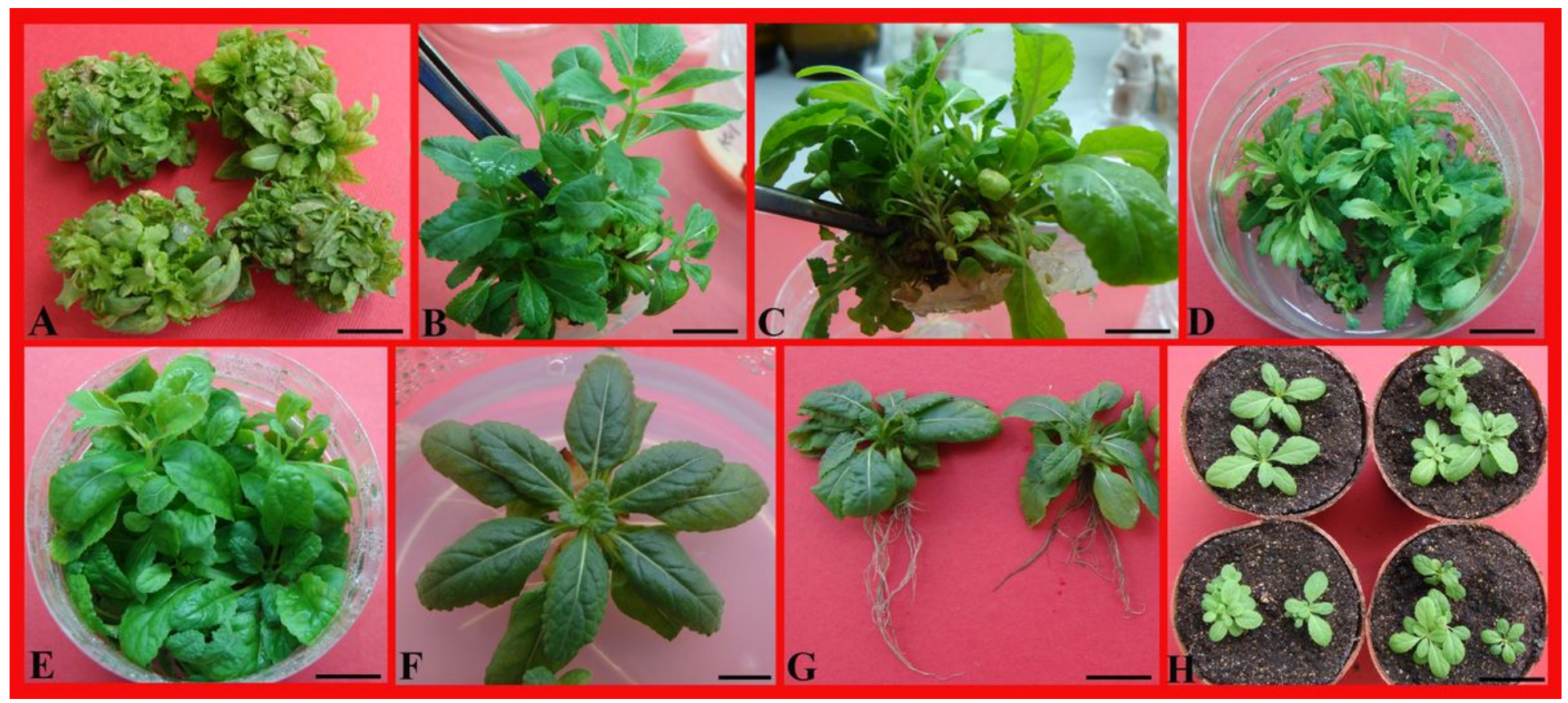

\section{Figure 5}

A Adventitious shoots on MS medium containing TDZ. B-E Elongated shoots from MS medium containing $0.5 \mathrm{mg} / \mathrm{L}$ GA3 in combination with $0.2 \mathrm{mg} / \mathrm{L} \mathrm{NAA}$ and $1.0 \mathrm{mg} / \mathrm{L} 6-\mathrm{BA}$. F and G Rooting of shoots on half-strength MS medium with $0.5 \mathrm{mg} / \mathrm{L}$ NAA. H Acclimatized plants from ex vitro rooting after 15 days. Bar $=1 \mathrm{~cm}(\mathrm{ABCFG}), 2 \mathrm{~cm}(\mathrm{DE}), 3 \mathrm{~cm}(\mathrm{H})$

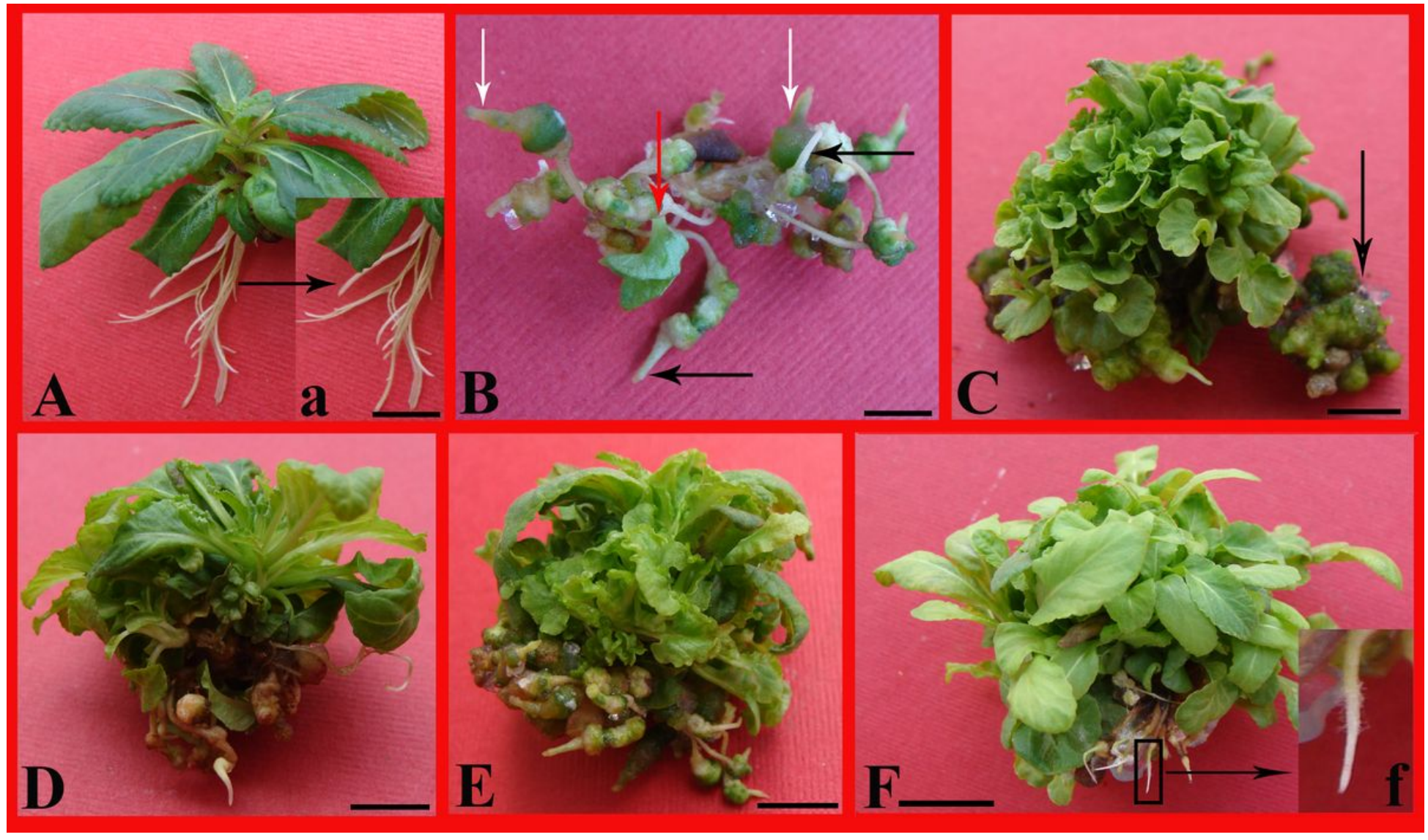




\section{Figure 6}

In vitro propagation from the adventitious root of Salvia plebeian. Root (a) of a regenerated plant (A). B Formation of green nodal callus from the adventitious roots after 14 days of culture (black arrow indicates root apices with physiological activity, white arrow indicates the induction of light green callus, and red arrow indicates shoot induction from green nodal callus). C, D and E Prolific shoot development from green nodal callus after 24 days of culture ( $C$ black arrow indicates shoot regeneration from green compact nodular callus). F Proliferation and development of shoot ( $\mathrm{f}$ indicates the root hair zone). Bar $=1 \mathrm{~cm}(\mathrm{ACDEF}), 5 \mathrm{~mm}(\mathrm{~B})$ 